\title{
An interprofessional approach to improving paediatric medication safety
}

Moira Stewart ${ }^{*}$, Joanna Purdy², Neil Kennedy, Anne Burns ${ }^{3}$

\begin{abstract}
Background: Safe drug prescribing and administration are essential elements within undergraduate healthcare curricula, but medication errors, especially in paediatric practice, continue to compromise patient safety. In this area of clinical care, collective responsibility, team working and communication between health professionals have been identified as key elements in safe clinical practice. To date, there is limited research evidence as to how best to deliver teaching and learning of these competencies to practitioners of the future.

Methods: An interprofessional workshop to facilitate learning of knowledge, core competencies, communication and team working skills in paediatric drug prescribing and administration at undergraduate level was developed and evaluated. The practical, ward-based workshop was delivered to $4^{\text {th }}$ year medical and $3^{\text {rd }}$ year nursing students and evaluated using a pre and post workshop questionnaire with open-ended response questions.

Results: Following the workshop, students reported an increase in their knowledge and awareness of paediatric medication safety and the causes of medication errors ( $p<0.001$ ), with the greatest increase noted among medical students. Highly significant changes in students' attitudes to shared learning were observed, indicating that safe medication practice is learnt more effectively with students from other healthcare disciplines. Qualitative data revealed that students' participation in the workshop improved communication and teamworking skills, and led to greater awareness of the role of other healthcare professionals.
\end{abstract}

Conclusion: This study has helped bridge the knowledge-skills gap, demonstrating how an interprofessional approach to drug prescribing and administration has the potential to improve quality and safety within healthcare.

\section{Background}

Safe drug prescribing and administration are essential elements within undergraduate healthcare curricula. However, a number of studies have reported that medical students feel unprepared for this aspect of clinical practice and on completion of undergraduate training they would not meet the competencies identified by the General Medical Council [1-3]. Nurses have reported limited understanding of pharmacology, dissatisfaction with the pre-registration teaching of the subject and feeling unprepared to perform certain tasks within nursing practice because of a lack of knowledge about the drugs they administer $[4,5]$.

Drug prescribing is very different in adult and paediatric practice. Infants and children are prescribed fewer drugs than adults, but are at a disproportionately higher

\footnotetext{
* Correspondence: m.c.stewart@qub.ac.uk

'Department of Child Health, Queen's University Belfast, Grosvenor Road, BT12 6BP, Belfast, Northern Ireland
}

risk of medication errors [6]. Drug prescribing and administration is more complex in children: drug doses need to be calculated on an individual basis taking into account gestation and postnatal age, weight and/or body surface area $[7,8]$. Drugs prescribed for children are often unlicensed and formulated for adults [9].

Medication errors, particularly in paediatric practice, have been attributed to a lack of knowledge and skills $[10,11]$ resulting from inadequate education and training $[7,12]$. Poor mathematical skills have been demonstrated among medical and nursing students, further increasing the risk of medication errors following qualification [13-15]. In addition, errors in drug prescribing and administration have been attributed to poor communication and lack of teamworking between healthcare professionals [16]. In paediatric practice, involvement of family members further complicates the prescribing process [17].

\section{()


Aim

The aim of this study was to develop and evaluate an interprofessional teaching and learning workshop of paediatric dug prescribing and administration for medical and nursing students, which would facilitate learning of knowledge, core competencies, communication and team working skills. In addition, rigorous evaluation of the workshop could inform curriculum development.

\section{Methods}

\section{The Centre for Excellence in Interprofessional Education (CEIPE)}

CEIPE was established to identify and develop opportunities within healthcare and other academic disciplines, to enhance students' team working and communication skills, promote collaborative practice and ultimately, improve patient care. In collaboration with the Schools of Medicine, Dentistry and Biomedical Sciences and Nursing and Midwifery at Queen's University Belfast, 'Paediatric Drug Prescribing and Administration' was identified as an appropriate area for teaching and learning in an interprofessional context for undergraduate medical and nursing students.

This work received approval from the Office for Research Ethics Committees Northern Ireland (05/ NIR01/167) on 4 January 2006.

\section{Interprofessional Education Group}

An interprofessional education (IPE) group comprising paediatricians, a paediatric clinical pharmacist, a nurse educator and research staff was established to develop and evaluate an interprofessional programme of teaching and learning to address medication safety issues in paediatric practice.

\section{Learning Outcomes}

The IPE group identified common learning outcomes (Table 1) for the workshop with particular emphasis on practical, communication and team working skills.

\section{Students}

Fourth year paediatric medical and $3^{\text {rd }}$ year children's branch nursing students had completed core teaching (see below) and were identified as the most suitable groups to participate in the workshop [18].

\section{Teaching programme \\ i. Core Teaching}

During the 'Healthcare of Children' module, $4^{\text {th }}$ year medical students receive a lecture in 'Pharmacokinetics and Prescribing in Infants and Children' delivered by a paediatric clinical pharmacist. Information is provided on children's physiological response to drugs, prescribing and dosage regimes and common causes of errors in paediatric prescribing. In year 2 of their degree, nursing students also receive teaching by a pharmacist, which includes paediatric drug dosage, drug interactions, legal aspects and calculations. Nurse lecturers deliver opportunistic teaching on drugs used for common conditions and their side effects during year 3 of the children's nursing curriculum.

\section{ii. Interprofessional Workshop}

A practical, ward-based workshop, facilitated by the IPE group on paediatric drug prescribing and administration was delivered to five groups of medical and nursing students during 2007-2008. Four 'real-life' clinical scenarios (Table 2) were constructed and included medications commonly used in paediatric clinical practice. Students were allocated to small interprofessional groups $(n=2$ 3 ) and were required to prescribe the appropriate drug, calculate the correct dosage, accurately complete a Drug Kardex, prepare the drug for administration, identify alternative drugs where appropriate, prepare an intravenous infusion and to be able to provide information to parents. The tasks varied in complexity and in the skills required, but all were dependent on students having prior knowledge of basic pharmacology and also on communication and team working, with complementarity of the specific uniprofessional expertise.

Table 1 Student learning outcomes for Paediatric Drug Prescribing and Administration Workshop

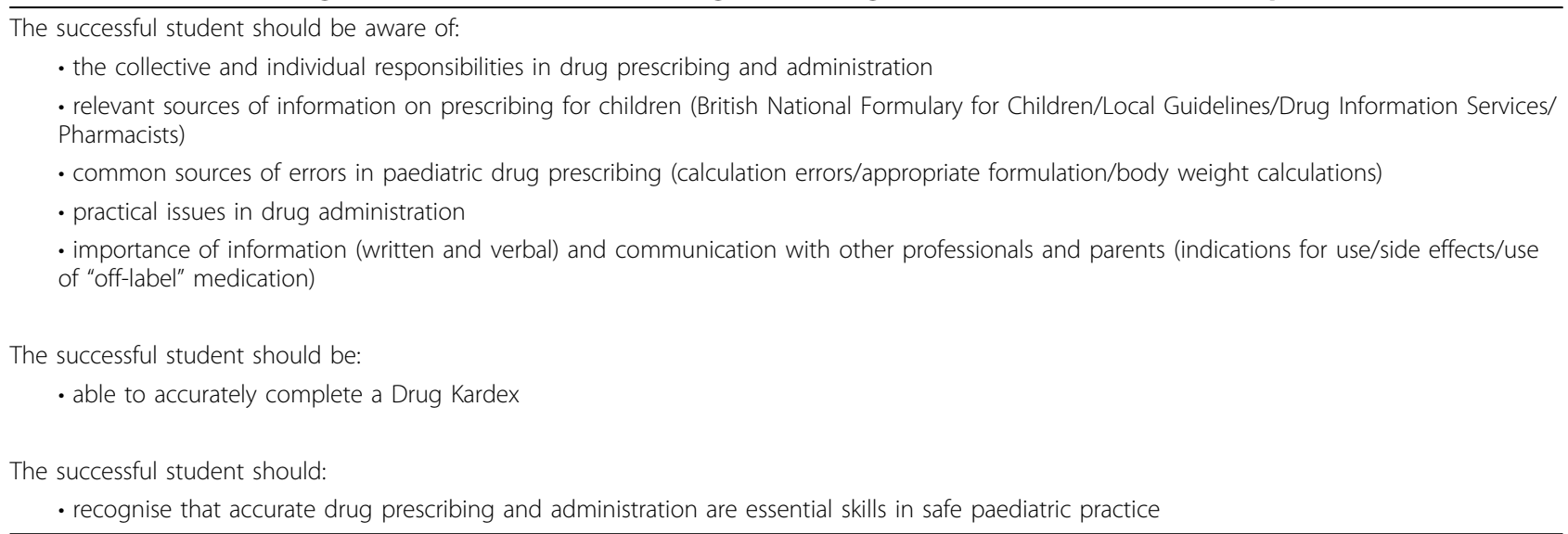


Table 2 Examples of 'Real-Life' Clinical Scenarios

\begin{tabular}{|c|c|c|c|}
\hline Summary of Clinical Scenario & Drug & Questions for students & Resources Required \\
\hline $\begin{array}{l}18 \text { month old admitted to hospital } \\
\text { following simple febrile illness. } \\
\text { Red ears and throat and probable viral } \\
\text { upper respiratory tract infection. }\end{array}$ & $\begin{array}{l}\text { Ibuprofen } \\
\text { or } \\
\text { Paracetamol }\end{array}$ & $\begin{array}{l}\text { 1. What is first line antipyretic agent? } \\
\text { 2. Calculate dose, complete Drug Kardex and } \\
\text { prepare for administration. } \\
\text { 3. When nurses try to administer drug, child screams } \\
\text { and spits it out immediately. What should be done } \\
\text { next? }\end{array}$ & $\begin{array}{l}\text { - BNFC } \\
\text { - Medicine (syrup, suppository, } \\
\text { tablet) } \\
\text { - Drug Kardex } \\
\text { - Discharge proforma } \\
\text { - Oral syringe }\end{array}$ \\
\hline $\begin{array}{l}7 \text { year old with chronic asthma who is } \\
\text { admitted with a severe acute attack. } \\
\text { Child regularly uses inhalers and oral } \\
\text { medication. } \\
\text { Child responds poorly to treatment with } \\
\text { oxygen, 'back-to-back' nebulisers and } \\
\text { steroids. }\end{array}$ & $\begin{array}{l}\text { Intravenous } \\
\text { Aminophylline }\end{array}$ & $\begin{array}{l}\text { 1. What dose should be prescribed? } \\
\text { 2. What other information is needed? } \\
\text { 3. Write a script for intravenous aminophylline } \\
\text { infusion. } \\
\text { 4. What monitoring is required? } \\
\text { 5. Make up an intravenous aminophylline infusion. }\end{array}$ & $\begin{array}{l}\text { - Intravenous Aminophylline } \\
\text { ampoules (2) } \\
\text { - Large } 20-30 \mathrm{ml} \text { syringe \& } \\
\text { needles } \\
\text { - NaCl } 0.9 \% 500 \mathrm{ml} \text { or } 5 \% \\
\text { dextrose \& fluid pump \& } \\
\text { associated giving set } \\
\text { - Filter needle } \\
\text { - 'Sharps box' }\end{array}$ \\
\hline
\end{tabular}

\section{Resources}

Student and tutor study guides were developed which included the learning outcomes, guidelines for conducting the workshop, four clinical scenarios and resources required.

Students received a certificate from CEIPE acknowledging their attendance and participation in the workshop to be included in their portfolio.

\section{Research and Evaluation}

The workshop was evaluated using pre and post-workshop questionnaires based on the previously validated 'Readiness for Interprofessional Learning Scale'[19,20]. The 19 statement questionnaire used a 5-point Likert scale, ranging from strongly disagree to strongly agree, and examined student attitudes to shared learning, development of communication and team working skills, knowledge and awareness of medication safety in children and awareness of professional roles and responsibilities. The questionnaire also included open-ended response questions, allowing students to comment on this particular interprofessional learning experience.

Pre-workshop questionnaires were completed by $4^{\text {th }}$ year medical students $(n=172)$ undertaking the Healthcare of Children Module. Post-workshop questionnaires were administered to the medical students $(n=48)$ who participated in the workshop during their paediatric clinical attachment in the Royal Belfast Hospital for Sick Children. Pre and post-workshop questionnaires were completed by $3^{\text {rd }}$ year nursing students $(n=21)$ who participated in the workshop (one post-workshop questionnaire missing).

\section{Data Analysis}

Questionnaire data were analysed using SPSS version 15.0. The 5 point Likert scale was converted to $0-100$. Factor analysis was applied to reduce the original 19 Likert scale questionnaire statements to a smaller number of agreed domains (Table 3). Chronbach's Alpha $(\alpha)$ measure of reliability was used to determine the internal consistency of each domain. Domains with a Cronbach's $\alpha>0.69$ were accepted as reliable and used in the data analysis [21]. A General Linear Model was used to compare mean pre and post workshop scores, taking account of group effects and group by time interactions. Further analysis used the same approach to compare mean pre and post workshop scores for each discipline.

The open-ended responses were thematically analysed using the principles of Grounded Theory [22]. The emergent themes were verified independently by two researchers $[23,24]$.

\section{Results}

The interprofessional workshop was conducted over five 2 hour sessions during the 2007-2008 academic year, with participation from 48 medical and 21 nursing students.

Analysis of the pre-workshop mean scores for the whole medical student group $(n=172)$ with those students who undertook their clinical attachment in the Royal Belfast Hospital for Sick Children revealed no significant differences between the groups. Therefore, it was deemed acceptable to use the pre-workshop responses for all 172 medical students. Nursing students ( $\mathrm{n}=21$ ) completed pre and post workshop questionnaires (one post-workshop questionnaire was not completed).

The demographic profile of the workshop participants is shown in Table 4. Almost half of the nursing students had a previous undergraduate degree and approximately two thirds of students had previous experience of interprofessional teaching and learning activities. One third of medical students $(\mathrm{n}=18)$ and almost all nursing students $(n=19)$ reported to have had previous teaching in drug prescribing and administration. 


\section{Table 3 Questionnaire statements categorised into 4 domains}

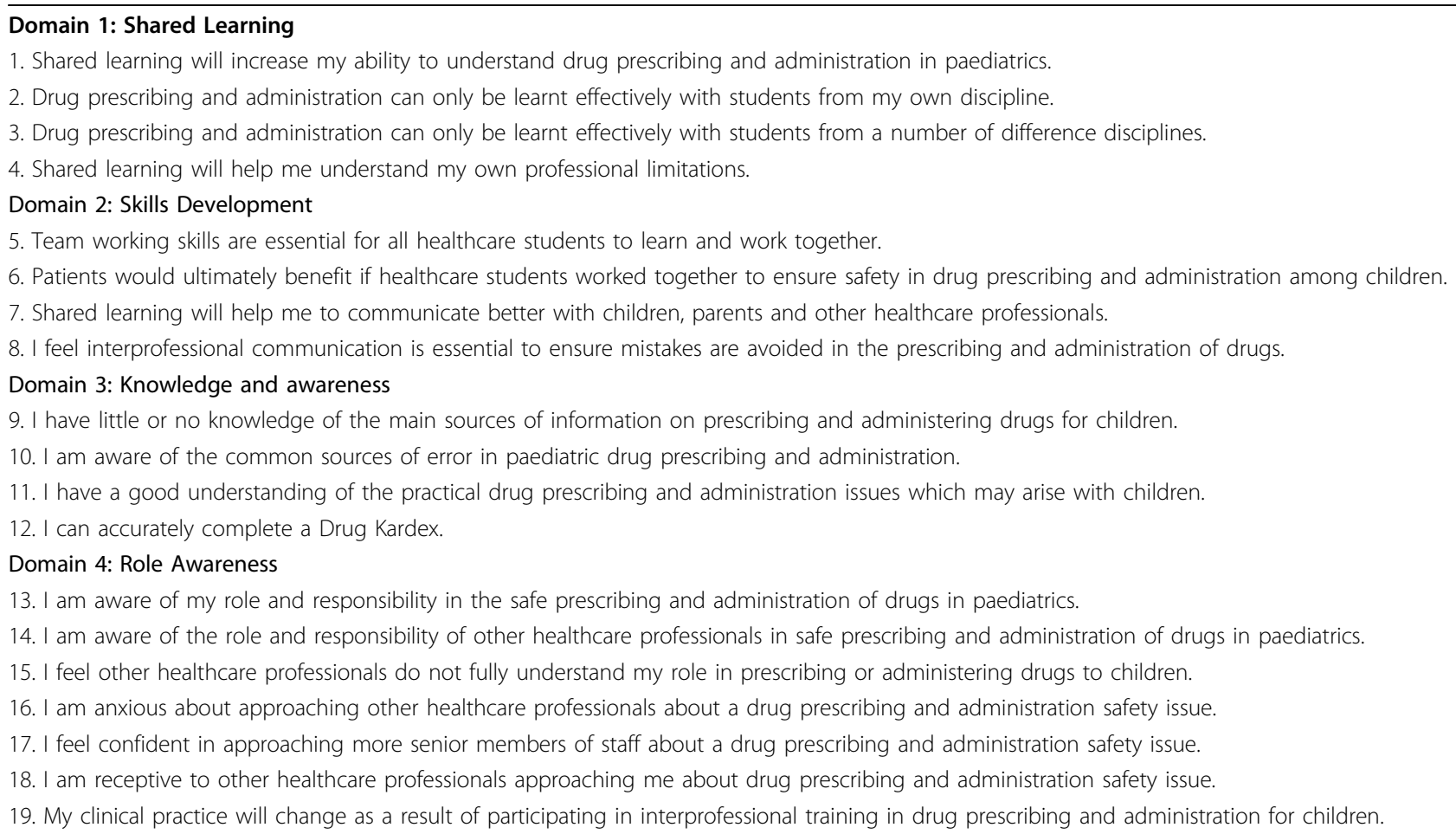

Following data analysis, the 19 statement questionnaire was reduced to 3 domains (Table 5). One domain (Role Awareness) was excluded from further analysis due to a Cronbach's Alpha score $<0.69$, indicative of poor internal consistency between the statements within this particular domain. The results from Tables 5, 6 and 7 are reported collectively by domain.

Pre workshop scores were high for all domains, indicating positive attitudes, particularly in the areas of shared learning and communication and teamworking.

Table 4 Demographic profile of workshop participants

\begin{tabular}{lcccc}
\hline & Male & $\begin{array}{c}\text { Medical } \\
\text { Students }\end{array}$ & $\begin{array}{c}\text { Nursing } \\
\text { Students }\end{array}$ & Total \\
\hline Gender & Female & 30 & 1 & 19 \\
Age & $18-22$ & 33 & 19 & 49 \\
& $23-28$ & 15 & 8 & 41 \\
& $29-34$ & 0 & 7 & 22 \\
Previous Degree & Over & 0 & 2 & 2 \\
\multirow{2}{*}{$\begin{array}{l}\text { Previous shared learning } \\
\text { experience }\end{array}$} & 34 & & 3 & 3 \\
& Yes & 1 & 9 & 10 \\
Previous related teaching & Yes & 18 & 11 & 58 \\
& No & 27 & 16 & 43 \\
& No & 30 & 19 & 37 \\
\hline
\end{tabular}

Mean post workshop scores (Table 5) indicate a positive shift in student attitudes to shared learning, communication and teamworking, and knowledge and awareness.

\section{Knowledge and Awareness}

The greatest change in students' responses was observed within the 'Knowledge and Awareness' domain, where a highly significant arbitrary difference was observed in pre and post workshop scores. Students reported considerable improvement in their knowledge and awareness of paediatric medication safety and the causes of medication errors. In particular, highly significant differences were observed in the medical students' mean pre and post workshop scores. Although similar post workshop scores were observed for both student groups, the reported increase was significantly greater for medical students (pre 43.0; post 65.9, p < 0.001) compared with nursing students (pre 65.2; post 72.2).

\section{Shared Learning}

Highly significant changes in students' attitudes to shared learning (pre 67.9; post 76.6; p < 0.001) were observed following the workshop. Students reported that paediatric drug prescribing and administration are learnt more effectively with students from other healthcare disciplines than in a uniprofessional context. Participation in the workshop also enabled students to recognise their own professional limitations. 
Table 5 Pre and post questionnaire mean domain scores for paediatric drug prescribing and administration workshop

\begin{tabular}{lcccc}
\hline Domains & \multicolumn{2}{c}{$\begin{array}{c}\text { Mean } \\
\text { Score } \\
\text { Pre }\end{array}$} & $\begin{array}{c}\text { Post } \\
\text { Difference }\end{array}$ & $\begin{array}{c}\text { 95\% Confidence } \\
\text { Interval }\end{array}$ \\
& 53.9 & 69.8 & 15.9 & $10.4-21.4^{* * *}$ \\
\hline $\begin{array}{l}\text { Knowledge and } \\
\text { Awareness }\end{array}$ & & & & \\
Shared Learning & 67.9 & 76.6 & 8.7 & $4.3-13.1^{* * *}$ \\
Communication and & 81.4 & 82.5 & 1.1 & $-2.6-4.9$ \\
Teamworking & & & & \\
\hline
\end{tabular}

${ }^{a}$ Adjusted for group effects and group by time interactions ${ }^{* * *} p<0.001$

Table 6 Pre and post workshop mean domain scores by discipline (medicine)

\begin{tabular}{|c|c|c|c|c|}
\hline \multirow[t]{2}{*}{ Domains } & \multicolumn{2}{|c|}{ Nursing } & \multirow{2}{*}{$\begin{array}{c}\text { Mean } \\
\text { Difference }\end{array}$} & \multirow{2}{*}{$\begin{array}{l}\text { 95\% Confidence } \\
\text { Interval }\end{array}$} \\
\hline & Pre & Post & & \\
\hline $\begin{array}{l}\text { Knowledge and } \\
\text { Awareness }\end{array}$ & 43.0 & 65.9 & 22.9 & $17.8-28.0^{* * *}$ \\
\hline Shared Learning & 67.4 & 76.7 & 9.3 & $4.0-14.6^{* * *}$ \\
\hline $\begin{array}{l}\text { Communication and } \\
\text { Teamworking }\end{array}$ & 81.1 & 83.9 & 2.7 & $-1.8-7.3$ \\
\hline
\end{tabular}

${ }^{\mathrm{b}}$ Adjusted for effects of previous teaching in this subject area ${ }^{* * *} \mathrm{p}<0.001$

Table 7 Pre and post workshop mean domain scores by discipline (nursing)

\begin{tabular}{|c|c|c|c|c|}
\hline \multirow[t]{2}{*}{ Domains } & \multicolumn{2}{|c|}{ Nursing } & \multirow{2}{*}{$\begin{array}{c}\text { Mean } \\
\text { Difference }\end{array}$} & \multirow{2}{*}{$\begin{array}{l}\text { 95\% Confidence } \\
\text { Interval }\end{array}$} \\
\hline & Pre & Post & & \\
\hline $\begin{array}{l}\text { Knowledge and } \\
\text { Awareness }\end{array}$ & 65.2 & 72.2 & 7.0 & $-1.1-15.1$ \\
\hline Shared Learning & 72.6 & 75.8 & 3.2 & $-5.5-11.8$ \\
\hline $\begin{array}{l}\text { Communication and } \\
\text { Teamworking }\end{array}$ & 83.3 & 80.3 & -3.0 & $-10.2-4.1$ \\
\hline
\end{tabular}

${ }^{\mathrm{b}}$ Adjusted for effects of previous teaching in this subject area

When analysed for group effects, there was a highly significant positive shift in medical students' attitudes to shared learning following participation in the workshop. Nursing students were more positive than medical students prior to the workshop which may account for the smaller increase in post workshop scores.

\section{Communication and Teamworking}

In the domain of Communication and Teamworking, no significant differences were observed in pre and post workshop scores, or within each discipline.

\section{Results from open-ended questions}

Three key themes emerged from the data - value of the learning experience, relevance to future practice and learning challenges.
Theme: Value of the learning experience

Students found the interprofessional workshop to be worthwhile, useful informative and enjoyable and a valuable practical learning experience. Medical students in particular, reported that this was their first opportunity to practise prescribing skills.

\section{Theme: Relevance to Future Practice}

A small number of students reported that the 'hands-on' experience, coupled with their clinical placement, would be of benefit in their future practice.

Practical points cannot be learned effectively from textbook. Worthwhile exercise following through with scripts and preparation. (Medical Student)

Students reported the experience was relevant to future practice as it increased knowledge of drugs, administration and prescribing and particularly of drug calculations, medication doses and preparation and the use of relevant sources of information. Students reported increased confidence resulted and that this was important for future practice. As well as increased knowledge students reported the experience improved their practical skills in prescribing, communication and team working.

Nursing students particularly recognised the potential benefits of learning and working together as a team.

To be able to work together with doctors and learn from each other. (Nursing Student)

Additionally, students reported that the interprofessional learning experience was relevant to future practice as it increased their awareness of medication errors common in paediatric practice and the role of other healthcare professionals in the drug prescribing and administration process. It also enabled them generally, to learn more about the role of other healthcare professionals which was reported as being relevant to future work.

\section{Theme: Learning Challenges}

Some students reported difficulty with the mathematical calculations, whilst others felt that more time should be allocated to the workshop to allow for more detailed consideration and discussion of the clinical scenarios. Students also reported that they would prefer an equal number of students from each discipline (in the present study this was not possible, since there are fewer nursing than medical students) and that they would benefit from greater insight into the role of the other healthcare professionals. Students also highlighted practical issues such as individual access to a British National Formulary, larger teaching space and more students participating in the workshop. 


\section{Discussion}

The design and delivery of this interprofessional workshop resulted in quantitative and qualitative evidence of improvement in clinical knowledge and skills and a greater awareness of the importance of shared learning. In addition, the qualitative data supported the value medical and nursing students placed on communication and teamworking skills in relation to learning and working together. Students were positive about the practical nature of the workshop, recognising its application to clinical practice in bridging the knowledge-skills gap in both prescribing and administration of drugs and awareness of potential medication errors. Their responses support the key elements for successful educational interventions, which emphasise the importance of a strong practical approach to teaching [25].

We attempted to address two issues when designing this workshop. Firstly, concerns among newly qualified doctors and nurses about their preparedness for safe drug prescribing and administration. Even though all students, medical and nursing, had been timetabled to have teaching in pharmokinetics, specific to paediatric drug prescribing and administration, two-thirds of medical students reported that they had not received any such teaching. This raises concerns about students' perception of the importance and relevance of theoretical teaching and their uptake of classroom based lectures in the absence of opportunities for practical application.

Secondly, in light of evidence of the importance of communication between healthcare professionals for safe medication practice, communication and teamworking and appreciation of the skills and expertise of other professionals were integral learning outcomes for the workshop. Evidence to date highlights the importance of communication between healthcare professionals for safe medication practice [16]. Failure in any one of these competencies can lead to a cumulative series of errors involving various members of the healthcare team, with adverse patient outcomes. In one study it was reported that $81 \%$ of medication errors could have been avoided with pharmacist monitoring, $47 \%$ could have been avoided by improved communication between physicians and pharmacists and $17 \%$ could have been prevented with improved communication between doctors and nurses [16].

If we accept the need for improved teaching and training of knowledge and skills required for safe drug prescribing and administration, it seems evident that equal attention should be directed to communication and teamworking skills. According to the World Health Organisation [26] communication and teamworking skills, essential for collaborative practice, are best learned in an interprofessional context, but debate continues as to the optimal stage of the curriculum at which interprofessional learning should be introduced and the environment in which it should be taught [27]. In this study, where the emphasis was on practical rather than theoretical aspects of paediatric prescribing and administration, there was qualitative evidence of the development of communication and teamworking skills. An interprofessional approach, involving students from different professional backgrounds has the potential to meet these various learning objectives and improve clinical practice.

It was apparent that students needed to have core clinical competencies and skills allied to their own profession in order to gain maximum benefit from the various learning opportunities offered by the workshop. Medical students in particular need to have basic mathematical skills, be aware of the various sources of information and able to accurately complete a Drug Kardex. These issues may need addressed at earlier stages in the curriculum.

Despite the resource implications, timetabling considerations and time and commitment required from educators to allow these workshops to be delivered, the positive evaluation supports the expansion of the workshops to other student groups and to include other prescribing areas. In other medical schools, $4^{\text {th }}$ year paediatric students and final year pharmacy students jointly participated in a paediatric workshop ${ }^{12}$ suggesting that this workshop is appropriate for other disciplines and has potential to be extended to other areas of clinical practice and to other paediatric medications.

\section{Conclusion}

This study has demonstrated that shared learning is an effective approach to achieving common learning outcomes for undergraduate medical and nursing students. Participation in the workshop has helped bridge the knowledge-skills gap and provided an opportunity for students to develop and enhance their communication and teamworking skills.

An interprofessional teaching and learning approach to safe paediatric drug prescribing and administration has the potential to improve quality and safety within healthcare. However, long term follow up is needed to determine if healthcare students are more competent practitioners following their participation in this study.

\section{Study limitations \\ Short term follow up}

It is unclear whether learning outcomes translate into improved safety in workplace.

IPE student groups limited to medical and nursing students. 


\section{Study implications}

Study addresses current safety concerns re drug prescribing and administration.

IPE approach facilitates communication and teamworking in addition to knowledge and skills.

Practical learning experience relevant to future practice.

Qualitative and quantitative evidence of benefits of IPE approach to learning, drug prescribing and administration.

\section{Acknowledgements}

The authors would like to thank colleagues from the School of Nursing and Midwifery for their contribution to this study and colleagues in the Royal Belfast Hospital for Sick Children for their co-operation and access to the necessary facilities and equipment. Thanks are extended to Mr Michael Stevenson for his assistance with statistical analysis and to Mrs Anne Montgomery for the qualitative analysis (School of Medicine, Dentistry and Biomedical Sciences) and to the Centre for Excellence in Interprofessional Education for funding the research and evaluation of this study.

\section{Author details}

'Department of Child Health, Queen's University Belfast, Grosvenor Road, BT12 6BP, Belfast, Northern Ireland. ${ }^{2}$ Centre for Excellence in Interprofessional Education, School of Dentistry, Queen's University Belfast, Grosvenor Road, BT12 6BP, Belfast, Northern Ireland. ${ }^{3}$ Royal Belfast Hospital for Sick Children, Grosvenor Road, BT12 6BP, Belfast, Northern Ireland

\section{Authors' contributions}

MCS: Planned, implemented and evaluated workshops. Principal author. JP: Co-ordination of workshops, major contribution to preparation of paper. AB: Planned and implemented workshop, expert advice on pharmacology of paediatric drug prescribing and administration. NK: Planned, implemented and evaluated workshops and advised on manuscript preparation. All authors read and approved the final manuscript.

\section{Competing interests}

The authors declare that they have no competing interests.

Received: 9 October 2009

Accepted: 19 February 2010 Published: 19 February 2010

\section{References}

1. Han WH, Maxwell SRJ: Are medical students adequately trained to prescribe at the point of graduation? Views of first year foundation doctors. Scottish Medical Journal 2006, 51:27-32.

2. Heaton A, Webb DJ, Maxwell SRJ: Undergraduate preparation for prescribing: the views of 2413 UK medical students and recent graduates. British Journal of Clinical Pharmacology 2008, 66:128-134.

3. Illing J, Morrow G, Kergon C, Burford B, Spencer J, Davies C, Baldauf B, Morrison J, Johnson N, Allen M, Peile E: How prepared are medical graduates to begin practice?. A comparison of three diverse UK medical schools London: General Medical Council 2008.

4. Manias E, Bullock S: The educational perspective of undergraduate nursing students in pharmacology: clinical nurses' perceptions and experiences of graduate nurses' medication knowledge. International Journal of Nursing Studies 2002, 39:773-7845

5. King R: Nurses' perceptions of their pharmacology educational needs. Journal of Advanced Nursing 2004, 45:392-400.

6. Kashual R, Bates DW, Landrigan C, McKenna KJ, Clapp MD, Federico F, Goldman DA: Medication errors and adverse drug events in paediatric inpatients. Journal of the American Medical Association 2001, 285:2114-2120.

7. Sammons $\mathrm{H}$, Conroy S: How do we ensure safe prescribing for children?. Archives of Disease in Childhood 2008, 93:98-99.

8. Wong ICK, Wong LYL, Cranswick NE: Minimising medication errors in children. Archives of Disease in Childhood 2009, 94:161-164.
9. Yeung YW, Tuleu CL, Wong ICK: National study of extemporaneous preparations in English paediatric hospital pharmacies. Paediatric and Perinatal Drug Therapy 2004, 6:75-80.

10. Simpson JH, Lynch R, Grant J, Alroomi L: Reducing medication errors in the neonatal intensive care unit. Archives of Disease in Childhood Fetal and Neonatal Edition 2004, 89:F480-F482

11. Aronson JK, Henderson G, Webb DJ, Rawlins MD: A prescription for better prescribing. British Medical Journal 2006, 333:459-460.

12. Conroy S, Carroll WD: Prescribing in paediatrics. Archives of Disease in Childhood Education and Practice Edition 2009, 94:55-59.

13. Rowe $T$, Koren $T$, Koren $G$ : Errors by paediatric residents in calculating drug doses. Archives of Disease in Childhood 1998, 79:56-58.

14. O'Shea E: Factors contributing to medication errors: a literature review. Journal of Clinical Nursing 1999, 8:496-504.

15. Glover ML, Sussmane JB: Assessing paediatric residents' mathematical skills for prescribing medication: a need for improved training. Academic Medicine 2002, 77:1007-1010.

16. Fortescue EB, Kashual R, Landrigan C, McKenna KJ, Clapp MD, Federico R, Goldmann DA, Bates DW: Prioritising strategies for preventing medication errors and adverse drug events in paediatric inpatients. Paediatrics 2003, 111:722-729.

17. Ong LML, de Haes JCJM, Hoos AM, Lammes FB: Doctor-patient communication: a review of the literature. Social Science and Medicine 1995, 40:903-918.

18. Morison S, Bohan M, Jenkins J, Moutray M: Facilitating undergraduate interprofessional learning in healthcare: comprising classroom and clinical learning for nursing and medical students. Learning in Health and Social Care 2003, 3:92-104.

19. Parsell G, Bligh J: Education principles underpinning successful shared learning. Medical Teacher 1998, 20:522-529.

20. Morison S, Stewart M: Developing interprofessional assessment. Learning in Health and Social Care 2005, 4:192-202.

21. Nunanly J: Psychometric Theory. New York: McGraw-Hill 1978.

22. Charmaz K: Constructing Grounded Theory: A Practical Guide Through Qualitative Analysis. London \& California: Sage Publications 2006.

23. Sim J, Wright C: Research in Healthcare: concepts, designs and methods. Cheltenham: Thornes 2000.

24. Pope C, Ziebland S, Mays N: Qualitative research in healthcare: Analysing qualitative data. British Medical Journal 2000, 320:114-116.

25. Conroy S, North C, Fox T, Haines L, Planner C, Erskine P, Wong I, Sammons $\mathrm{H}$ : Educational interventions to reduce prescribing errors. Archives of Disease in Childhood 2008, 93:313-315.

26. World Health Organisation: Learning together to work together for health. WHO Technical Report Series 769 Geneva: World Health Organisation 1988.

27. Hammick M, Freeth D, Koppel I, Reeves S, Barr H: A best evidence systematic review of interprofessional education: BEME Guide no. 9', Medical Teacher. 2007, 29(8):735-751.

\section{Pre-publication history}

The pre-publication history for this paper can be accessed here:http://www biomedcentral.com/1472-6920/10/19/prepub

doi:10.1186/1472-6920-10-19

Cite this article as: Stewart et al:: An interprofessional approach to improving paediatric medication safety. BMC Medical Education 2010 $10: 19$ 